\title{
Payment and the sick poor
}

In 1935 Sir Alan Garrett Anderson, son of the pioneer of women in medicine, Elizabeth Garrett Anderson, was elected Conservative MP for the City of London. A year later he spoke in a parliamentary debate on the nation's voluntary hospitals:

We have been told that they are passing through a lean time and are in competition with the municipal hospitals, but I demur to both those statements. The hospitals are always short of cash, because they are doing a great and expanding work, but they are getting enormous voluntary support from the whole class who will be treated in the hospitals all over the country. I do not think that 'a lean time' is the correct expression. They are being more and more useful as the community learns the importance of health, and the provision of health is getting more and more expensive. During the last 10 or 15 years there have come into being more and more departments which are like telescopes to look inside us and prevent disease before it begins. Those departments are very expensive, and that is why the balance sheet is difficult to balance; and, without help from all the patients, the hospitals would, of course, have broken down, and there would have been a great disturbance of the whole health service. ${ }^{1}$

Put plainly, the interwar era was a time when hospitals could do more but afford less. In this context, we can see a reluctant adoption of patient payments as the chosen means to survive. The question this prompts is the extent to which philanthropy as the organising principle of the voluntary hospital system was undermined or even abandoned by this decision.

Charity was not crowded out by the expanding public sector in the early twentieth century, but neither did it continue unchanged. As 
discussed in the previous chapter, the voluntary sector expanded in partnership with the state. In Bristol as elsewhere, the voluntary hospitals were just one area in which this was the case. However, the relationship between the voluntary hospitals and the state was not always an easy one. The hospitals' involvement in meeting the demands of the First World War was the most bruising example of government being ready to ask more but unwilling to pick up the tab. The financial strains were exaggerated by a challenging postwar economic climate, increasing demand and ever greater technological requirements in hospital medicine. As the new decade of the 1920 s beckoned there were genuine grounds for optimism in the growing capabilities of hospital medicine, yet placing the work of the voluntary hospitals on a sound financial footing was an even harder task than usual. A new settlement was required - a new contract with the traditional working-class patient, represented by the character of 'George' in the 1948 cartoon Your Very Good Health - in which payment was to become an important feature.

The fundamental question this chapter seeks to answer is whether the incorporation of payment into this revised patient contract amounted to an abandonment of philanthropy. The appointment of hospital almoners to conduct what was effectively a means-test served as a double-safeguard. First, it allowed the hospital to grant reductions and exemptions to those unable to pay, ensuring this did not become a barrier to access. Second, along with the setting of income limits, the assessment of the almoner was a mechanism for weeding out those of the middle and upper classes who were not considered appropriate cases for medical charity. Beyond mere safeguards, however, the new mechanisms and rituals of payment came to reinforce philanthropy in a variety of ways.

\section{Systems of admission}

Prior to the First World War, Bristol's voluntary hospitals were typical in operating two well-established systems for admission: subscriber's tickets and 'receiving day'. In Mary Fissell's study of the eighteenthcentury origins of the Bristol (later Royal) Infirmary, she discussed the former, emphasising its characteristics of dominant philanthropist and passive recipient. According to this arrangement, the Bristol Infirmary was founded and primarily maintained by charitable donations, in 
return for which subscribers were entitled to nominate deserving sick individuals for admission. This 'new channel for paternalism' was purchased at the rate of two guineas a year for one inpatient and up to three outpatients at a time. ${ }^{2}$ Although as many as a third of subscribers never made use of this entitlement in the Bristol Infirmary's first century, it was important both for patients, because a subscriber's ticket was necessary for all but emergency admissions, and for maintaining 'networks of patronage.".

As Fissell has explained, 'the recommendation from a hospital supporter required by a prospective patient' was 'a form of social exchange in a face-to-face society. The hospital provided an arena for the mediation of social power, both directly through individual patronage, and symbolically through civic ritual and display. This face-to-face encounter would often be with someone familiar to the individual through 'residential proximity, employment' or 'religious affiliation.5 It was an 'articulation of social difference' between these self-styled 'stewards of the poor' and the recipients who had to prove themselves deserving not only of medical treatment but also capable of 'moral reform. ${ }^{6}$ The subscriber was therefore a powerful figure in this 'gift relationship', discriminating between those suitable for hospital treatment and 'the less worthy paupers who resorted to the workhouse." A fictional portrait of the system appeared in Elizabeth Gaskell's 1848 novel Mary Barton, with its subtitle 'A Tale of Manchester Life':

'If you please, sir,' said a servant, entering the room, 'here's one of the mill people wanting to see you; his name is Wilson, he says.'

'I'll come to him directly; stay, tell him to come here.'

Amy danced off into the conservatory which opened out of the room, before the gaunt, pale, unwashed, unshaven weaver was ushered in. There he stood at the door sleeking his hair with old country habit, and every now and then stealing a glance round at the splendour of the apartment.

'Well, Wilson, and what you want to-day, man?'

'Please, sir, Davenport's ill of the fever, and I'm come to know if you've got an Infirmary order for him?'

'Davenport - Davenport; who is the fellow? I don't know the name.'

'He's worked in your factory better nor three years, sir'.

'Very likely; I don't pretend to know the names of the men I employ; that I leave to the overlooker. So he's ill, eh?' 
'Ay, sir, he's very bad; we want to get him in at the Fever Wards.'

'I doubt if I've an in-patient's order to spare at present; but I'll give you an out-patient's and welcome.'

So saying, he rose up, unlocked a drawer, pondered a minute, and then gave Wilson an out-patient's order.

Meanwhile, the younger Mr Carson had ended his review, and began to listen to what was going on. He finished his breakfast, got up, and pulled five shillings out of his pocket, which he gave to Wilson as he passed him, for the 'poor fellow.'

By the early twentieth century, there was significant criticism of the recipient's powerlessness in this relationship: 'Can you imagine the feelings of the dissenting agricultural labourer in a small village who has to go to the vicar for a subscriber's letter? Or those of the village socialist who has to submit to a political lecture from the squire before he can get one?"

This system was not particular to the Bristol Infirmary and became the standard means of accessing services as the voluntary hospital system expanded through the eighteenth and nineteenth centuries. ${ }^{10}$ In the latter, however, admission directly by doctors increasingly became an alternative, including at the Bristol Infirmary. This system, where patients would come to the hospital on a 'receiving day' and be seen by a doctor, was the only means of being admitted to the Bristol Royal Hospital for Sick Children and Women from its foundation in $1866 .{ }^{11}$ 'Enough that a child be sick and poor', the institution's annual reports declared, 'it will be admitted provided there be an empty bed and that the Medical Officers consider the case a suitable one for admission to the hospital. ${ }^{12}$ By doing so, they were adhering to the principle Dr William Marsden established in 1828 in founding the Royal Free Hospital in London, that 'destitution and disease should alone be the passport for obtaining free and instant relief'. ${ }^{13}$ In this alternative, however, even with medical examination replacing the moral subjectivity of the recommendation, the patient remained in an essentially passive role.

For most voluntary hospitals in Bristol, however, admission by means of the subscriber recommendation system continued into the twentieth century. Whereas the subscriber ticket was being phased out of many voluntary hospitals around the turn of the century, those hospitals in Bristol, alongside others including the Birmingham Infirmary and Guy's Hospital, 'retained it in the belief that the issue of subscribers' 
letters was necessary to sustain the enthusiasm of charitable supporters'. This was an important consideration at a time of declining subscriber income, as noted by Gorsky, Mohan and Powell for the voluntary hospitals, and by Daunton for associational voluntarism more widely. ${ }^{14}$ Recommendations also continued at the Radcliffe Infirmary in Oxford, where subscribers' notes known as 'Turns' made one guinea exchangeable for the admission of one inpatient or four outpatients until 1926. ${ }^{15}$ In some rare cases, such as the Saturday Fund in Nottingham, it was not until 1938 that subscriber recommendations were abandoned. ${ }^{16}$

Over the 1920s most hospitals gradually replaced recommendations with a new arrangement, whereby admission became an entirely medical matter but payment was increasingly a term of that admission. Payment by patients was not entirely unknown before the twentieth century, as Jonathan Reinarz has demonstrated with a number of examples from eighteenth- and nineteenth-century Birmingham. ${ }^{17}$ However, it was not until the start of the 1920s that it became the norm and ingrained in both hospital administration and patient experience. In place of a subscriber judging deservingness, a medical social worker, known in our period as the Lady Almoner, carried out an assessment. It was her task to determine both what further support was necessary and what would be an appropriate financial contribution to ask. The two ways to avoid paying the almoner were either to be deemed unable to pay, something beyond the control of the individual patient, or to be a member of a hospital contributory scheme. This would involve paying a weekly subscription of perhaps two or three pence from weekly wages into a workplace or local fund, the scheme would then cover a contribution on behalf of the patient if admitted.

The recent literature on the pre-NHS hospital sector has rightly given a prominent place to such schemes. ${ }^{18}$ They have been characterised as becoming 'an essential element of the British hospital system' in the interwar decades, enabling 'renewed hospital expansion. ${ }^{19}$ Certainly, they were a notable change and provided a useful new income stream - but they are not themselves the whole story. As Martin Gorsky and John Mohan calculate, by the mid-1930s hospital contributory schemes accounted for something in the region of one-third of income for large hospitals across Britain, more than double the amount coming from direct patient payments. ${ }^{20}$ This does not mean, however, that twice as many patients were contributory scheme members as not. Exemptions 
or reductions regularly granted to non-members, as well as grants made to the hospitals by contributory schemes separately from the payments on behalf of their members when hospitalised, mean there is no direct correlation to be drawn between the number of patients in each category and the income derived from them.

In Bristol we see contributory schemes only gradually established over three decades. The first schemes were small workplace ones, not accompanied by a city-wide scheme until 1927 when the Bristol Medical Institutions Contributory Scheme (BMICS) was established. It was hoped this would bring the level of membership in Bristol up to that of the movement's leading lights; yet a decade later campaigners could still point enviously to cities like Sheffield and Liverpool where membership was roughly between one-third and a half of the whole population (including the dependants expected to be covered by the head of the household), and Birmingham where it was well over half. A rival central scheme, the Bristol Hospitals Fund (BHF), was set up in 1939 under the closer control of the hospitals themselves, which does appear to have closed the gap. In the early 1940s, combined membership of the $\mathrm{BHF}$ and the Bristol Hospital Contributors League, which brought together the BMICS and the independent workplace schemes, was in the region of 150,000 - more than one-third of the city's population at the time. This proportion was significantly greater than in nearby Cardiff although far less than in Swansea, which was home to the biggest hospital contributory scheme in Wales. There were, therefore, two decades during which it was the norm for patients to pay something to the hospital before Bristol's population adopted a mass-scale membership of the contributory schemes in the 1940s. While the contributory schemes should not be dismissed, they should also not be treated as synonymous with the patient experience in those final decades before the introduction of the NHS. Of greater importance were the more quickly established direct patient payment schemes.

The rest of this chapter will examine the workings of and relationship between these two parallel systems for working-class patients and potential patients making a contribution. Above all, the two will be shown as alternative arrangements for the same act: not buying medical care or even gaining admission, but rather for working-class patients themselves to be enlisted as charitable donors to the hospital. 


\section{Patient payment schemes in Bristol}

\section{Payment in the voluntary hospitals}

In the summer of 1921, in response to the financial difficulties of the years immediately following the First World War, the city's first direct payment scheme was jointly introduced at the Bristol Royal Infirmary and the Bristol General Hospital, side-lining the nominally continued subscriber's tickets. Under this system admission was essentially a clinical decision, but the patient was then expected to contribute towards the cost of their maintenance. These new arrangements were reported in the Bristol Times and Mirror:

(1) In-patients, with the exception of necessitous cases, will be charged

21s. per week towards the cost of their maintenance.

(2) Out-patients, with the exception of necessitous cases, will be charged a registration fee of $6 \mathrm{~d}$. for each attendance, and an additional $6 \mathrm{~d}$. for medicine or dressings, etc., when supplied. X-ray, electrical and massage treatment to be charged for specially, according to the cost.

(3) Insured patients will be required to bring a note from their panel doctor stating that hospital out-patient treatment is necessary, and they will be charged the same rate as other patients. ${ }^{21}$

By December of that year these arrangements had been replicated at the Bristol Eye Hospital, and it was later to become the model for the Bristol Homeopathic Hospital. ${ }^{22}$ The patient payment scheme introduced at the Bristol Royal Hospital for Sick Children and Women differed in both its rate of contribution and its geographical qualification. Bristol's Children's Hospital had never taken notes of recommendation, sharing the belief at the Birmingham Women's Hospital that women should not need 'to explain their complaints to anyone but a medical gentleman. ${ }^{23}$ In accordance with this ethos it had previously admitted children up to the age of thirteen free and women according to their means. ${ }^{24}$ Under the new arrangements, however, a weekly contribution of five shillings was asked of patients living within a twenty-five mile radius of Bristol, and this was doubled for non-local patients, with the burden of patients from South Wales cited as a factor. ${ }^{25}$

The standard rate of one guinea per week had been introduced at the Norfolk and Norwich Hospital only a year before the joint scheme in 
Bristol, and this was taken as the template. ${ }^{26}$ One guinea was generally said by the hospitals to be significantly less than the average cost of providing treatment; which the Homeopathic Hospital claimed in 1937 to be $£ 33 \mathrm{~s} 4 \mathrm{~d}$ per week. ${ }^{27}$ Yet a guinea was also a significant amount to pay, twice what the average working-class family in the late 1930s spent on a week's rent and two-thirds of that on food. ${ }^{28}$ In Bristol in the 1920s it would have been around a third the weekly wage of a shipbuilding labourer and half that of a building or engineering labourer. ${ }^{29}$ The local press echoed a joint sub-committee of the two institutions in presenting exemptions from the standard rate of contribution as being for 'really necessitous cases' only. ${ }^{30}$ This perhaps contributed to the long-standing perception that 'the contribution was a form of compulsory payment. ${ }^{31}$ However, in practice, exemptions from and reductions to patient payments were extensive.

The exemptions and reductions offered by the almoner allowed the Bristol Royal Infirmary to claim that no patient who is financially unable to make a contribution' was expected or even 'asked to do so.' ${ }^{\text {'2 }}$ The level of full or partial exemption from contribution was vast. If universally upheld, the new payment scheme would have generated over $£ 10,000$ in its first year; the actual figure was $£ 2,968 .{ }^{33}$ Although this more than doubled the following year, the degree of exemption remained high enough for Labour Alderman Frank Sheppard, the longserving deputy then chairman of the city's municipal health committee, to tell the institution's governors it 'clearly showed that they had not received payment from those who were not in a position to make it. $\mathrm{He}$ emphasised this point 'because of the misunderstanding which had arisen over the contribution of a guinea a week. ${ }^{34}$ No doubt this confusion had been aided by the hospitals' using the language of charges to announce the scheme. ${ }^{35}$ Meanwhile, at the Bristol Homeopathic Hospital in 1937, the work of the almoner's department was said to have 'progressed satisfactorily', largely due to an increase in the number of patients who 'were either without means or only able to contribute very little towards the One Guinea per week contribution asked for, in the General Wards. ${ }^{36}$ Treating those who could not afford to pay, rather than generating higher income from those who could, was the marker of success.

Figures 3.1 and 3.2 show the proportion of patients receiving such exemptions and reductions at the Bristol Royal Infirmary and the 
Bristol General Hospital respectively. They cover the period from the first full year of the payment scheme until reported figures do not allow for such distinctions. For both, it should be noted that payments on behalf of patients are included as well as those directly by the patients themselves. Therefore contributory schemes, as well as charitable or public bodies sponsoring patients, are an unmeasured and inseparable proportion of that category. From the outset, it was noted at both hospitals that local workplace schemes accounted for the majority of payments of one guinea or more. ${ }^{37}$ Meanwhile, those admitted entirely free became a smaller proportion of those admitted to both. However, while Cherry has asserted that patient payments became 'generalized' over this period, ${ }^{38}$ in Bristol's two major general voluntary hospitals at least, free and subsidised treatment continued to be a major feature of the institution.

The hospitals therefore admitted a mix of patients throughout the interwar years as the new system bedded in and payment became the norm. Some were passed free. This category continued, although it

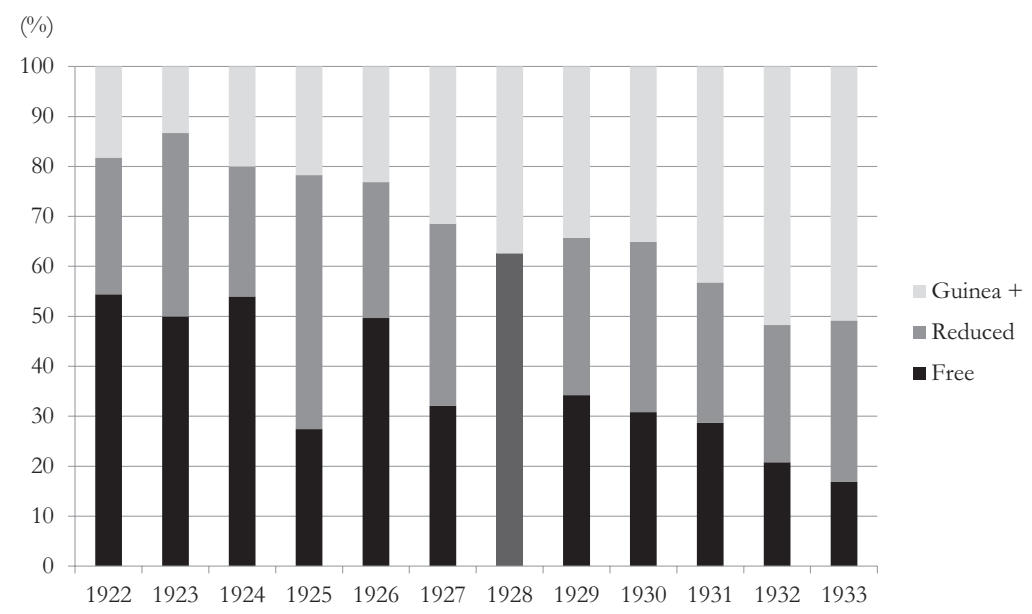

Figure 3.1 Proportions of patients paying different rates at the Bristol Royal Infirmary, 1922-33

Note: Figures given for 1928 do not allow for a distinction between reductions and exemptions. 


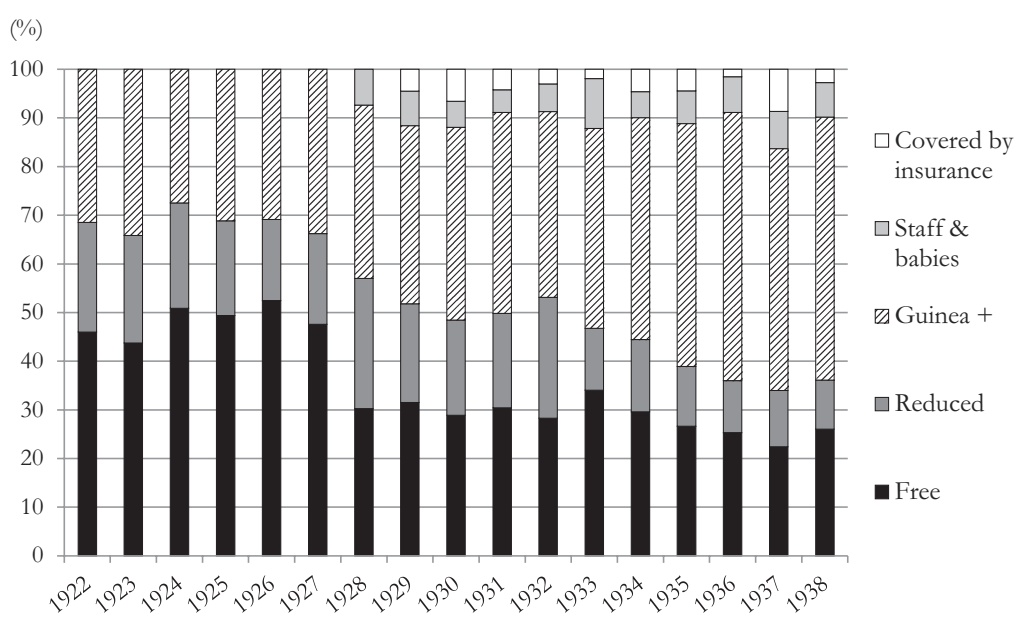

Figure 3.2 Proportions of patients paying different rates at the Bristol General Hospital, 1922-38

halved at the Bristol General Hospital and fell further and quicker at the Bristol Royal Infirmary, where patients were more likely to pay at a reduced rate instead. Those cases where the institution received the full guinea payment or more (either from the patient directly or on their behalf) had only grown to approximately half of all inpatients by the mid-1930s. From this time onwards it grew further, although those receiving admission free or at a reduced rate remained above 40 per cent even after the two hospitals amalgamated in 1939. The variable but consistently significant proportion of patients in these free and reduced payment categories was said to be determined largely by the state of the local economy, increasing at times of high unemployment. ${ }^{39}$

This high rate of free admission cannot be dismissed as a consequence of contributory scheme membership being smaller in Bristol than some other cities, as seen from Nottingham, where scheme members accounted for 60 per cent of patients. The Nottingham General Hospital fell between Bristol's two general voluntary hospitals, with one in five deemed unable to pay and admitted free..$^{40}$ Meanwhile the figure was one in ten at the city's Eye Hospital, despite historian Nick Hayes judging the institution 'financially punctilious' and eager to 
limit free admissions. ${ }^{41}$ In the annual reports of Bristol hospitals, almoners repeatedly claimed that 'inability to make a contribution' had never led to a patient being refused treatment, and that offers had been rejected when 'the money was needed in the patient's home, or to tide over the period that might intervene between leaving the Infirmary and a return to work. ${ }^{32}$ This was seen in action retrospectively in 1925 when one patient's payments at five shillings a week were refunded after it was brought to the House Committee's attention 'that it was a very great hardship to her to pay anything. ${ }^{43}$ However, it should be noted that this example could be used to support either the argument that payments were declined or that the assessments may not have guaranteed that all individuals unable to pay were admitted free. Either way, it is clear payment was not a fixed price but was constantly negotiated and renegotiated on the basis of the patient's circumstances.

Across the city's voluntary hospitals, therefore, we see a mixed system developing, according to which contributory scheme members and other funded patients were increasingly admitted to the general wards alongside philanthropically subsidised patients. This description fits those paying the full guinea rate, which was approximately only one-third of the full cost of maintenance, as well as those admitted free or at a reduced rate.

\section{Payment at the municipal hospitals}

It is easy to cast interwar municipal hospitals as forerunners of the National Health Service, providing tax-funded medical services to the whole community and making important strides towards a more integrated and co-ordinated hospital system. ${ }^{44}$ Not always, however, services free at the point of use. A similar payment system to that of the voluntary hospitals was also to be found at Bristol's municipal Southmead Hospital. An early 1930s Ministry of Health survey noted that 'if treated in the general wards the fee is $£ 2.2 .0$ ', twice the full rate at the voluntary hospitals, with higher fees again for middle-class patients in private rooms (discussed in the next chapter). ${ }^{45}$ The principle underpinning this gradation of payment was said to be that the sick poor would have first claim upon the accommodation at Southmead, but any citizen would have the right to apply for a bed at the Hospital, subject to the condition of paying all or part of the cost, if able. ${ }^{46}$ 
Little has been written in previous studies to suggest how widespread this approach was in public infirmaries. However, Doyle has noted 'the charging of non-pauper paying patients $£ 110$ s per week', a significantly lower rate, at a similar institution in Middlesbrough. ${ }^{47} \mathrm{He}$ has also found paying patients alongside paupers in the poor law infirmaries of Leeds and Sheffield from the mid-1920s, prominent amongst whom were maternity cases and hospital contributory scheme members. ${ }^{48}$ What this suggests is that there was likely a now-forgotten practice of pre-NHS municipal hospitals charging patients akin to that of the voluntary sector. Indeed, under the 1929 Local Government Act it was 'the duty of the Corporation ... to recover the cost of treatment from all patients who are able to pay. ${ }^{49}$ However, the public hospitals in Bristol seem to have gone far beyond their legal duty and the higher rates charged suggests they may even have embraced this more eagerly than their voluntary counterparts.

The matter was addressed further by the city's municipal health committee in 1933, in a discussion of Southmead's expanding specialist maternity provision. The Liberal chairman, H.J. Maggs, said the rates charged at Southmead were still low enough to show the development of its services as a municipal general hospital was intended for the treatment of what he called 'the hospital class of patient'.

It must be stressed again that in the extension of facilities at Southmead the accommodation was for the class of patient who could not afford treatment other than in a hospital; your Committee were not considering any other class. That it is this class who are availing themselves of the facilities at Southmead is shown by an analysis of the maternity cases admitted in 1932. The scale of charges are such that a man (with wife and one child) who earns more than $£ 119 \mathrm{~s} 2 \mathrm{~d}$ per week (net income) is assessed to pay the full cost of treatment. Approximately 56 per cent. of the cases admitted in 1932 fell below this standard and 30 per cent. (approximately) were unable to pay anything at all, and were given free treatment. There were several more on the borderline, and although assessed to pay the full charge they were unable to do so. ${ }^{50}$

Reflecting the similarities between the voluntary and municipal hospital payment schemes, Southmead appointed an almoner in April 1937. ${ }^{51}$ The figures in her annual reports to the city's Medical Officer of Health (given in figure 3.3) demonstrate that the mix of patients paying 


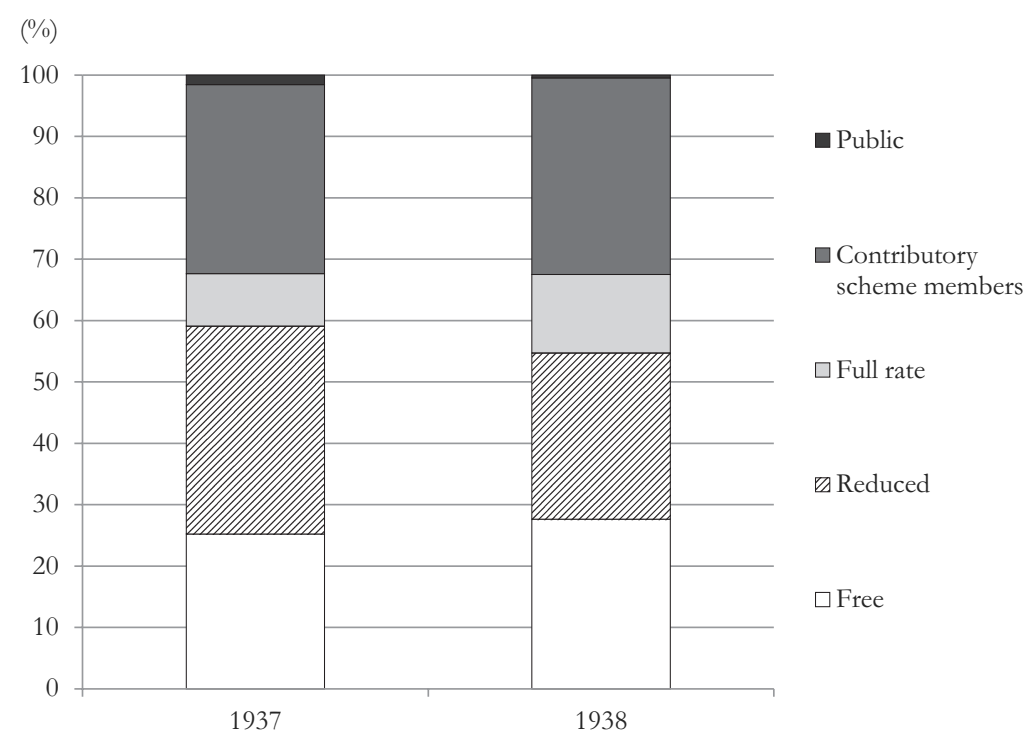

Figure 3.3 Proportions of patients paying different rates at Southmead Hospital, 1937-38

different rates was strikingly similar to the voluntary hospitals. There are two differences we can note. One is that payments from contributory schemes and public bodies are given separately from those patients paying the full rate here. What this different method of recording the figures reveals supports the assertion of the voluntary hospitals that the majority of those paying the full rate were contributory scheme members. We might expect them to be patients in the voluntary hospitals, which had a far better-established working relationship with the contributory schemes, yet at Southmead they accounted for nearly onethird of patients. For contributory scheme members in Bristol, as in London and elsewhere, it would appear the development of maternity and other services made Southmead an acceptable alternative to either of its voluntary counterparts, despite the ongoing stigma of having been a workhouse infirmary. ${ }^{52}$

The other difference is the greater proportion of patients paying at a reduced rate. However, this is easily explained by the fact that the full 
rate was two guineas instead of the one asked for in the voluntary hospitals. As such, it is clear that the interwar years saw a common system of means-tested financial contribution (although not commercial fees) established in general wards across the public/voluntary hospital divide in Bristol.

\section{Reluctant change}

Although the reasons for introducing such schemes were varied, there does not appear to have been any great degree of zealotry about taking a step towards a commercial model of provision, even from those at the hospitals most actively pressing for the introduction of payment schemes. ${ }^{53}$ At the Bristol Royal Infirmary the Faculty were concerned that 'the admission of the cases for payment would give them priority and would thus still further diminish the accommodation for the suffering poor. ${ }^{54}$ When five honorary staff members addressed the institution's General Committee in 1920, they explained that they were 'merely anxious that the long Waiting Lists of Patients should be admitted, it being evident that, at present, this could only be done if some form of payment was received from those who could afford it. ${ }^{55}$ As such, financial rather than ideological motivations were paramount. ${ }^{56}$

The financial imperative to consider the introduction of pay beds was considerable. A 1919 committee meeting had 'unanimously agreed that at present it was impossible to increase the number of free beds at all' at the Bristol Royal Infirmary, 'and that the provision of paying beds should be considered at once. ${ }^{57}$ A year later the number of beds was restricted to 238, only to be increased if the full cost of the bed could be paid to the hospital. ${ }^{58}$ The Bristol Times and Mirror reported 'the important new direction' as one the hospital's governors had 'been forced to take', which was 'inevitable if the work were to be continued in any degree according to need. ${ }^{59}$ There were reformers elsewhere who advocated payment on more than strictly financial grounds. Though when Robert Hogarth called for a payment scheme in Nottingham, 'not simply a matter of maximizing income' but to encourage a collective sense of ownership and of entitlement to treatment, he found he was voicing an unpopular opinion. ${ }^{60}$ For most of those engaged in establishing hospital payment schemes, the reason for doing so was overwhelmingly one of financial necessity. 


\section{The Lady Almoner}

When payment schemes were introduced, the task of achieving that difficult balance between generating new income and maintaining a philanthropic ethos typically fell to a new figure in the voluntary hospitals: the Lady Almoner. Yet she is a figure often found in the background if not entirely omitted from the recent historical literature. Former almoners writing on their profession's history include Angela Simmons' postgraduate work, in which she located early pioneers firmly within a late-Victorian social context. ${ }^{61}$ Phyllis Willmott's narrative of the first fifty years of the almoner profession (until 1945) emphasised the role of various London-based committees in building the profession. ${ }^{62}$ Meanwhile, some historians have also tentatively turned their attention to the almoner.

Keir Waddington located the initial introduction of almoners in London firmly within the late nineteenth-century debate around outpatient abuse. ${ }^{63}$ Lynsey Cullen has added to this by conducting the first rigorous investigation of the archival records of an almoner's department, using this source to better understand the patient intake and range of diseases, as well as the contribution of the almoner to their care. Her focus was restricted to the first almoner, Miss Mary Stewart, appointed at the Royal Free Hospital in London in 1895 and retiring in $1899 .{ }^{64}$ Rona Dougall and Chris Nottingham's work on Scottish social work within the NHS, identifying it as an 'insecure profession', is unusual for bringing the story so far into the twentieth century. ${ }^{65}$ For the most part the limited literature on the almoner profession remains heavily focused on its earliest days and on London. What this misses is the rapid and widespread growth of the profession beyond the capital in the interwar years. One historian to venture into this territory is Elaine Thomson, describing the Edinburgh Hospital for Women and Children's almoner as 'keeping working-class patients under surveillance in their own homes', reflecting her role at a very specific type of voluntary hospital. ${ }^{66}$ Another local case study by Barry Doyle has found the Leeds General Infirmary to have appointed an almoner in 1910, rather earlier than most provincial towns, with appointments in other hospitals following in the 1920s. While they balanced financial and social support roles, their counterparts in nearby Sheffield adopted a greater focus on after-care in the later 1930s. ${ }^{67}$ 
While these contributions are very welcome, they fall far short of providing a coherent picture of the profession as a whole across Britain and over the half-century before the introduction of the NHS changed their function fundamentally. It is therefore worth briefly considering how the profession was understood at the time.

\section{The almoner profession: finance and social work}

A common theme running through the contemporary literature on the almoner was a tension between the social work side of the almoner's role and their involvement with patient payment schemes. Dorothy Manchée, almoner at St Mary's Hospital in London, wrote a pseudoautobiographical novel which she called Whatever Does an Almoner Do? She wrote it, in part, in the hope of 'combating the unfortunate and incorrect impression of many lay people that "she interviews patients' relatives about fees"! ${ }^{68}$ In one passage, where the almoner is talking to a young woman considering the profession, the author takes the opportunity to dispel some common misconceptions:

'Being an Almoner', Ann Clavering explained, 'is rather like being a Universal Aunt. Everyone in the hospital and many outside come with their troubles and problems for us to help solve. We find homes for babies and jobs for cripples; extra food for the hungry and extra money for the needy; glasses for those who can't see and wheel chairs for those who can't walk. Sometimes we are asked for paper carriers and drawing pins! The man-in-the-street usually thinks we collect money for the hospital, and that's about the only job we don't do!'

'I thought you asked people what they earned and told them what to pay for their treatment,' said Yvonne in astonishment.

'The Almoners in some hospitals do so because they believe that they know the patients best and so can be more fair to them, but at this hospital we don't even do that. We're just here to help people get the best advantage from their hospital visits. ${ }^{39}$

This was one of a number of books published on the eve of the NHS seeking to clarify the role of the hospital almoner and distance her from financial assessment, perhaps prompted by concern that if the profession was too closely associated with patient payments it would be seen as superfluous under the new system.

From the appointment of the first hospital almoner, the focus was on the financial side of the role. When the Charity Organisation Society 
(COS) caseworker Mary Stewart was appointed, she was given three duties: to prevent the 'abuse' of admission being given to 'persons able to pay for medical treatment'; to refer the 'destitute' to the Poor Law; and to encourage those between the two to join 'Provident Dispensaries' whenever financially possible. ${ }^{70}$ This was said to be a 'largely negative programme' compared to the 'positive ideals' espoused by COS founder, Sir Charles Loch, when he suggested to a House of Lords Select Committee four years earlier that hospitals should appoint some form of 'charitable assessor, or co-operator ... well instructed as to all forms of relief other than medical. ${ }^{71}$ However, the profession quickly adopted this financial focus. Even before the First World War, both the Hospital Almoners Committee (the national association of almoners) and the Hospital Almoners' Council (which dealt with training and qualifications) had placed tackling 'abuse' at the heart of their definitions of the role. ${ }^{72}$

Once hospitals had appointed almoners in order to serve this financial role, the almoners themselves pushed for a move towards a greater emphasis on social work. For example, Alan Moncrieff, Nuffield Professor of Child Health at the University of London, wrote in 1948 that in the half-century since the appointment of the first almoner:

medical-social work has moved away from the narrow conception of negatively preventing abuse of the hospital's charity towards the positive aspect of contributing to the diagnosis and treatment of disease by providing the medical staff with details of the social background against which the patients' symptoms must be judged, and his or her treatment adjusted. ${ }^{73}$

This finance-first narrative fits the case of Bristol, where almoners were introduced with a clear focus on recovering payment over social work. The appointment of the city's first almoners came alongside the 1921 introduction of a payment scheme. Similarly, almoners began to be appointed in public hospitals - beginning with Surrey and London only in the 1930s, when 'appropriated' municipal hospitals had a duty to recover their costs from patients where possible. ${ }^{74}$

Whether the financial side or social work is said to have come first, the professional literature was agreed on the eventual primacy of the social work aspect. This was perhaps most forcefully asserted by Flora Beck, a social worker and social work scholar attached to the Nuffield Department of Medicine: 
The almoner is a social worker in a medical setting, and medical social work differs from other forms of social work only in this, that its particular concern with social problems is in relation to health and sickness. Social case work has been defined in this context as 'the art of helping people, both through the best use of their own capabilities and through the resources of the community, to overcome personal and social difficulties, and to achieve the fullest possible measure of health and independence. ${ }^{15}$

A similar view was expressed in a mid-1930s report of the almoner's department at Addenbrooke's Hospital in Cambridge, which makes no mention of payment whatsoever:

Each Department of the Hospital sees the patient from a different angle. In the Almoner's Office he is no longer the gangrenous appendix, the obstinate arthritis, or the glaucoma that has responded so well to treatment, but an ordinary human being with his background of ordinary human cares and relationships. He is for us the out-of-work trying to balance a budget that can never quite meet the household needs; an Old Age Pensioner without kith or kin; a child whose future still hangs precariously in the balance. Through the Almoner's Office pass all the types which go to make up the Hospital world, the lonely, the misfits, the discouraged and the difficult - all through sickness or poverty, in need of some help or advice. ${ }^{76}$

It is certainly true that assessment for financial purposes was only one of many jobs carried out by the almoner. In some unusual cases, alternative arrangements relieved them of this responsibility altogether. For example, at King's College Hospital: 'If you didn't produce your voucher, or the promise of it, you put something in a box. You kind of bought a ticket and so the medical social workers there didn't have any responsibility for assessment. ${ }^{77}$ Even where they did conduct financial assessments they might not always be the top priority. One former almoner recalled her attitude years later, which she found an easier fit with working in a London County Council institution, rather than a voluntary hospital: 'If I've got several people outside my door in outpatients with difficult problems, and others are just waiting for me to assess whether they can manage one and sixpence per attendance or not, there is no question in my mind where I'm going to spend the time. ${ }^{, 78}$ This became easier still during the Second World War, which another almoner remembered as 'a great opportunity, because the 
emergency medical service which was a trial run for the National Health Service, put an end to all these patients' payments and things. The contributory schemes kept on, but they took care of so much that gradually the almoners were able to get out of that administrative chore. $^{79}$

Beyond financial assessments almoners took on a wide range of roles more easily understood as 'social work'. These included giving advice on hospital procedures, public benefits and how to make medically necessary changes at home and work. They arranged transfers to other institutions, including admission to a convalescent home, established rehabilitation plans and organised after-care visitations. It fell to them to find emergency accommodation for patients' relatives when they were admitted and ensure that family and community networks of support were in place when they were discharged. They might also act as a patient's advocate to secure public or voluntary services, such as funded admission to an appropriate special school for a sick child. The task was theirs of making practical arrangements for surgical appliances, such as artificial limbs or hearing aids. The professional literature said it was also their job to deal with 'misfits', including 'employable cripples' and the 'mentally handicapped." ${ }^{\prime 0}$ In this role, the almoner therefore served as a link between the medical and social worlds and to see the patient not merely as a "case" but as a distinctive personality. ${ }^{\text {, } 11}$ As this involved directing patients to support from both public and voluntary sources, the almoner profession has been said to embody the interweaving of statutory and voluntary service' historically characteristic of the British welfare system, operating at the hub of its mixed economy. ${ }^{82}$

In Bristol, the almoner's focus was on assessments for the payment scheme and the financial side of the role, even if they might have wished otherwise. This was demonstrated, for example, by the Bristol Homeopathic Hospital judging the almoner's work in 1937 to have been satisfactory due to the continued increase in the number of patients 'who are members of Contributory or Works Medical Charity Schemes. ${ }^{83}$ Similarly, the appointment of a second Assistant Almoner was 'justified' on the grounds that it would generate 'a still further rise in income, and in an increase of general efficiency. ${ }^{84}$ Meanwhile 'after-care' work was given a 'comparatively small amount of time. ${ }^{85}$ Across Bristol's hospitals this was a secondary aspect of the role, but not an entirely overlooked one. The substantial work of almoners in securing continued support 
after discharge was an important contribution to the integration of local care services across the mixed economy of welfare. ${ }^{86}$

'Very frequently the best and most useful social work consists not in any material form of help,' the Bristol Royal Infirmary's almoner noted in 1922, 'but in the establishment of the friendly relation with the patient, which makes it possible to give advice and guidance of real value. ${ }^{87}$ To this end, 'home visits' also featured as part of the almoner's after-care work in her reports. ${ }^{88}$ By the late 1920 s, the practice had developed whereby subscribers to convalescent homes would send their recommendation tickets to her for use in the after-care referral of hospital patients. ${ }^{89}$ In this respect, she was part of the wider network of voluntary healthcare and charitable institutions. This was also seen in 1931, when 'a grant was made from Clifton College Chapel Sick and Poor Fund to be used at the Almoner's discretion for needy patients. ${ }^{90}$ She was also engaged with voluntary efforts at the hospital itself; for example in encouraging the establishment of a Samaritan Fund to support the non-medical needs of patients, eventually set up at the Bristol Royal Infirmary in 1938, a decade after that of the Bristol General Hospital. ${ }^{91}$ The department would also commonly organise free rail travel, or the lending of a motor car for transporting patients unable to travel by bus or train, to hospital or convalescent homes: 'The patients themselves constantly affirm that to be taken to Weston or Clevedon by car is the "best bit" of the Convalescence!" Comments in the almoner's report for the Infirmary in 1937 suggest the department was involved in road accident cases, both providing grants until insurance claims might be resolved but also gathering evidence to support those claims. $^{93}$

The close working relationship between the almoner's department and charitable organisations outside the hospital, as well as the traditional charitable subscribers to the hospital, emerges in the very first almoner's report for a Bristol hospital:

A.B., a girl of 14 years, was in the Women's Medical Ward suffering from acute Chorea. It was not the first attack and during her short life she had been several times in the Infirmary. The child's father was an invalid and as the mother had to go out to work, there was no one to look after the patient after her return home. She was quite unfit to work and would have been left to her own devices all day long. By the doctor's advice the Almoner sent A.B. for two months to the Herbert Home at 
Bournemouth. It was necessary to obtain four subscriber's 'letters' which reduced the weekly charge to 9s. 6 . The Civic League made enquiries into the case and raised the necessary money, the child's mother paying part of the weekly charge, A.B. returned from Bournemouth very much improved in health and the doctor pronounced her fit for work.

A light place has been found for her in service and she is being kept under Medical observation from the Infirmary. ${ }^{94}$

\section{Almoning as a career}

Clearly the almoner was an important figure in the voluntary hospital, yet we know little about who became almoners or their career paths. We do know the almoner profession was a 'predominantly female' one in contrast to the typically male enquiry officers who preceded them. ${ }^{95}$ Indeed, the case of Thomas William Cramp, Outpatient Inspector from the 1890s turned almoner at the Metropolitan Hospital in London between 1902 and 1923, was a rare occurrence and merited special attention in posterity. ${ }^{96}$ Given the notable involvement in the domestic arrangements of patients we can place the almoner firmly within the 'feminine public sphere', able to draw upon the moral authority of the middle-class woman over working-class motherhood and domesticity. ${ }^{97}$ Yet at the same time, amongst female careers, the position of almoner conferred both high status and reasonably high pay.

Before the First World War, an almoner's salary was advertised as between $£ 100$ and $£ 200$ per year, up to ten times that for general domestic servant at the time. ${ }^{98}$ In the 1930s, starting salaries were often three times those of nurses. ${ }^{99}$ Almoning was a career for educated women, but it was not amongst the best paid, with higher salaries available in education and the Civil Service. Graduate female teachers in secondary schools earned $£ 359$ a year on average in 1923 , while the few women in senior administrative Civil Service posts a decade later earned more than $£ 700$ a year. ${ }^{100}$ Yet such salaries were far from the norm for working women. In her 1935 advice for women seeking careers, feminist Ray Strachey wrote that 'At present wages range, roughly speaking, from $£ 1$ to $£ 4$ a week, and salaries from $£ 3$ to $£ 5$; and the numbers of women workers who earn more than this are inconsiderable' and ' $£ 250$ a year is quite an achievement, even for a highly qualified woman with years of experience..101 While she described social work as a career 'undertaken in a vocational spirit', with salaries of 
around $£ 150$ 'not good', almoners' salaries were higher, typically between $£ 200$ and $£ 300 .^{102}$ By 1942 , the Institute of Hospital Almoners was recommending almoners be paid a yearly salary according to the following scale:

Head Almoner with assistants

$£ 350-£ 500$ per annum

Single-handed Almoner

$£ 250-£ 350$

Assistant Almoner with experience

$£ 225$ minimum

Assistant Almoner in first post four years 103

This level of pay required significant training. In Bristol this involved two years' study at university as well as placements with hospitals and the Council of Social Service. In the late 1930s, the Bristol Royal Infirmary's almoner described the role of their students:

We have two or three students each term who are studying for their Social Study Diploma, and they are able to concentrate on visits to the patients' homes; in this way it is possible to keep in touch with many patients requiring assistance with Housing conditions, advice on difficult diets, to say nothing of the number of problems surrounding those who are discharged before they are fully able to take up their normal livelihood again. In return these students obtain valuable experience, and contacts with different aspects of Hospital life and administration. In addition to the University students the Institute of Hospital Almoners send students for their one or two months' Provincial training during which time they are able to see the full work of the department. ${ }^{104}$

In fact, the University of Bristol was one of only thirteen institutions where these necessary courses could be taken. Three of the others were in London: Bedford College, King's College of Household and Social Science and the London School of Economics. The only others in the provincial south were Oxford School of Social Study and Southampton University College (until 1939). The others were Leeds, Liverpool, Birmingham, Manchester, Nottingham, Edinburgh and Glasgow Universities. ${ }^{105}$ As such, Bristol was a regional centre in the development of the almoner profession just as much as it was for medical services. Consequently, the almoner profession may well have been more developed or better supported in Bristol than in some other cities. 
Having undertaken this training, almoners played what was widely understood to be an important social role. As Jane Lewis commented, the almoner 'was perceived as the person responsible for forging the crucial links between individual, family and community, and hence to the wider society and state. ${ }^{106}$ Indeed, in the almoner profession we can see women 'able to exercise considerable influence on the direction of social provision' at the point of delivery. ${ }^{107}$ Taking on such a role was in turn an implicitly political act, fitting as it did the description of 'useful public service' that was one of the four demands set out in a Labour Women editorial in 1922 calling for greater political engagement. ${ }^{108}$

\section{Almoners and patients}

The first point of contact between the almoner and the patient would take place in her office for outpatients, as shown in figure 3.4, and usually on the ward for inpatients. ${ }^{109}$ One professional guide described the task:



The Almoner of The Great Northern Hospital at Work.

Figure 3.4 Almoner interviewing patients in London hospital, c.1920 
At her first interview with a patient, the almoner has two important things to do. The first is to determine whether social problems are likely to have a bearing on the patient's illness. The second is to make the patient feel that here is a person with whom he could, if necessary, discuss his personal difficulties; someone to whom he need not mind admitting any trivial misunderstanding which had been bothering him, and to whom he could reveal serious and confidential problems without embarrassment. ${ }^{110}$

During this interview, the almoner would endeavour to establish 'the income and the chief items of expenditure of a family, the type of work on which its members are engaged, and later on such salient facts as their religion and amusements, as well as the characteristics of the home.' This could then be followed up by further investigation, where necessary and with the patient's agreement, by seeking information 'not only from the patient, but also through other social agencies, from relatives, from employers, or from other sources'; and with inpatients 'by consultation with the sister of the ward? ${ }^{111}$ In the professional literature it was said to be a 'golden rule' that this should take place after the patient had seen the doctor, so that admission should be a medical matter and such financial considerations secondary. ${ }^{112}$ What is less clear is whether this distinction had any meaning for the patients themselves.

Although in the professional debates of the day much was made of the tension between these social and financial roles of the almoner, there was in practice something of a natural fit between them. Beck gave two reasons for the almoner's practice of 'social enquiry' into the personal circumstances of the patient. They were, first, 'to discover whether social factors such as poverty, bad housing, unsuitable working conditions, or personal worries and maladjustments may have affected the illness'; and, second, 'to get as complete a picture of the personal, social and economic background as may be necessary when social assistance is required. ${ }^{113}$ An omitted third was that it informed the level at which a financial contribution would be requested. As Manchée noted, it was because the almoner was approaching the patient holistically that she was seen as being most capable of making these investigations and judging the individual's ability to pay in a 'fair' way. ${ }^{114}$

Indeed, when in December 1935 the Glasgow Royal Infirmary introduced 'a three month experiment empowering the almoners to 
encourage patients who could afford it to contribute something towards their maintenance', they believed the almoner could administer such a scheme 'in a kindly and judicious manner without giving the slightest cause for resentment on the part of any patient. ${ }^{115}$ Beck similarly described the relationship between the almoner and the patient as a cordial one, realistically responding to changing times:

Since almoners first started their work the function of the hospitals has itself changed; what used primarily to be charities dispensing free medical treatment to those who could not afford a general practitioner's fee have gradually been transformed into centres for specialist treatment which could not be obtained outside. The relationship between patient and hospital has changed accordingly, and in recent years the majority of patients have been anxious to make sure that the hospital received payment from a contributory scheme or some other source, or else themselves to pay on a business-like footing for services received. ${ }^{116}$

The evidence is mixed on whether or not patients perceived this to be the 'fair' system described by practitioners. While Steven Cherry has suggested that almoners 'were often resented', the few surviving accounts display a wider range of responses. ${ }^{117}$ One woman, born in 1930, has recalled: 'An august but very kind lady called the Lady Almoner would come round the wards and inquire as to a patient's financial resources. If you could you would make a contribution. If not, there was no pressure or feelings of shame. Very benign I remember. ${ }^{\text {,118 }}$ Another, less positive, reference to the almoner can be found in the memoir of Bella Aronovitch, who was moved around a variety of London hospitals in the late 1920s when suffering with appendicitis. She recalled:

A few days after this first operation I had a visit from the hospital almoner. She came into the ward carrying a huge sheaf of papers and looked terrifyingly efficient. Following a few minutes' talk with Sister she came over to me, made herself comfortable on a chair beside my bed and for the next quarter of an hour, her conversation consisted entirely of questions. She started with questions about my family. How many of us were at home? Who went to work and who were still at school? How much did I earn when I went to work? How much rent did we pay? What was our total income from all sources? etc., etc. Now all the questions were the preliminary skirmishes to the final question, which was; could my family afford to pay towards my upkeep while I was in hospital and if so, 
how much? ... I found all those questions rather trying. However, I answered them as truthfully and to the best of my ability. As the almoner left, she told me to be sure to tell my mother to call at her office next mid-week visiting day. She then double checked with Mother on the answers to all questions. ${ }^{119}$

Falling somewhere between those accounts, and echoing the idea that payment was not explicitly optional, an oral history project conducted into health services in Lancashire suggests that there was some understanding of the non-compulsory nature of such systems. Mrs Carson (born in 1902) recounted outpatients being treated free and inpatients being sent 'a bill': 'They didn't force you to pay it, but they would ask you to pay something or make a donation to the hospital if [you] couldn't afford to pay the bill, with more or less everybody paying something.' When scalded at work she ended up spending her twentyfirst birthday at Lancaster Infirmary. She recalled: 'I got a bill for it. Six bob a day. ${ }^{120}$ More critically, in an article celebrating the sixtieth anniversary of the NHS, one trade unionist wrote the following:

During the second world war a woman is discharged from a south London hospital. Before she leaves the building with her young son they must see the Lady Almoner, who will determine the fees she must pay for her treatment and medicine.

The Lady Almoner sits behind a large wooden desk. She quizzes the woman about her household finances, the income and savings of everyone in the family and their daily standard of living. The interrogation over, the woman takes out her purse, pays the sum demanded, and leaves.

It is an upsetting and humiliating experience for my mother. For me, it is an early introduction to the world of means testing. ${ }^{121}$

There is, therefore, a significant diversity of experiences of the almoner among the few recorded. A similar range is suggested locally by comments that 'In almost every case the patients have been very ready to pay what they could afford' alongside long-running complaints about the misconception of compulsory fees. ${ }^{122}$ These varied reactions and recollections suggest that patient responses to the almoner 'ranged from deferential gratitude to pragmatic acceptance to outright resentment', just as Martin Gorsky has noted for recipient responses to Victorian philanthropy. ${ }^{123}$ Indeed, we should understand the experience of being assessed by the almoner as a philanthropic encounter. 


\section{Hospital contributory schemes}

Just as there was confusion over almoner-assessed payment, commonly mistaken for compulsory charges, there was confusion over what benefits could be purchased by membership of a hospital contributory scheme. It was not unusual to join a scheme in order to secure a form of social insurance, and this was something greatly encouraged in the promotion of the schemes (discussed further in chapter 5). The contributory schemes, however, did not provide medical insurance. Strictly speaking, members did not have any additional right of access. The British Hospitals Contributory Scheme made it plainly clear that a contributory scheme: 'Is not an Insurance Scheme, but is a Voluntary Organisation'. Membership, they insisted, 'cannot give any right to contributors to admission to any Hospital, nor any priority right in regard to order of admission', which they said were 'medical questions outside the scope of a Contributory Scheme'.

The privileges of the Scheme in regard to Hospitals commence to operate after the patient has been admitted to Hospital for treatment, and should be limited to securing for the Contributor immunity from any payment towards cost of maintenance in Hospital. Where the privileges of the Fund are based on income limits, the Contributory Scheme should also secure the Contributor immunity from questions in regard to his or her circumstances. ${ }^{124}$

Rather than insurance, therefore, we should understand contributory schemes as part of a tradition of hospital fundraising. Indeed, they were not the first efforts designed to encourage donations and contributions from the working classes. Hospital Sunday was introduced locally to raise funds for the Bristol Royal Infirmary and the Bristol General Hospital in $1860 .{ }^{125}$ By the First World War, works governors committees had become more common. By these means, local workpeople donating were represented on the management boards of the Bristol Royal Infirmary, the Bristol General Hospital and Cossham Memorial Hospital. ${ }^{126}$ Other typical forms of donation included collection boxes, which were especially promoted by one Bristol contributory scheme in the 1930s. Working-class attitudes towards collection boxes may, in some cases, have mirrored those expressed in the Edwardian novel The Ragged Trousered Philanthropists, which sought to document working-class life: 
On the ledge of the little window through which their [wages were] passed there was always a Hospital collection-box. Every man put either a penny or twopence into this box. Of course, it was not compulsory to do so, but they all did, because they felt that any man who omitted to contribute might be 'marked'. They did not all agree with contributing to the Hospital, for several reasons. They knew the doctors at the Hospital made a practice of using the free patients to make experiments upon, and they also knew that the so-called 'free' patients who contribute so very largely directly to the maintenance of such institutions, get scant consideration when they apply for 'free' treatment, and are plainly given to understand that they are receiving 'charity'. Some of the men thought that, considering the extent to which they contributed, they should be entitled to attention as a right. ${ }^{127}$

\section{Contributory schemes in Bristol}

Once payment schemes were introduced as a means of eliciting a financial contribution from patients, questions were raised about those who had already contributed in response to these fundraising efforts. There was, at least in theory, a standing arrangement at the Bristol Royal Infirmary, in a by-law dating from the appointment of the almoner, that 'where previous arrangements have been made for the contributions payable, no enquiry shall be made. ${ }^{128}$ This would allow for treatment free at the point of need for all those who had subscribed to a workplace fund. Despite this, it appears the medical faculty were committed to the notion that the only distinctions between patients should be medical ones. ${ }^{129}$ They insisted it was a matter of principle that 'preferential treatment is not given to any patients', regardless of protestations from the local contributing firm, J.S. Fry and Sons, that 'some scheme should be devised whereby those who contribute to the Infirmary Funds should have priority over those who make no contribution. ${ }^{130}$

The momentum for a change in the hospital's position appears to have built up during the middle of the decade, while the governors were considering the development of a public contributory scheme along the lines of the pioneering Sheffield penny-in-the-pound scheme, which had been established in $1922 .{ }^{131}$ Representatives of various Bristol hospitals met in 1926 to discuss establishing a city-wide contributory scheme. The objectives of the scheme were planned to be 'the raising of Funds for the upkeep of all Institutions of the list, and on behalf of those entitled to benefit, making provisions for the whole or part 
payment of the charges for maintenance at the same'; whereas admission would be determined by the hospitals, considering only 'the necessity of the case'. Any question of payment would thereafter be a separate consideration. ${ }^{132}$ When the BMICS was established a year later, however, it developed along lines quite different, leading the hospitals to set up the $\mathrm{BHF}$ as their own rival scheme after twelve years of disagreement on a number of issues. One was whether it was preferable to collaborate with the great number of independent local and workplace schemes, each setting their own rate of subscription, or to unify contributory effort in the city. The BMICS saw itself as working with the smaller schemes and for its members, who had majority control on its governing committee, whereas the BHF worked hard to amalgamate the independent schemes and bring them under the direction of the hospitals. For the BHF, therefore, the proper role of the contributory scheme was more simply as a fundraising adjunct of the hospital. ${ }^{133}$

Despite tensions between the two schemes, there was in fact a degree of unspoken consensus on the question of the range of services to be provided. In 1935, the BMICS set up an Extended Benefits Scheme, which offered cash benefits to contributors when they were admitted to hospital, as well as additional surgical services or convalescent home care. ${ }^{134}$ The BMICS was proud that this new scheme was 'the first of its kind in the United Kingdom', and it has been considered a pioneer by historians (since most contributory schemes in the 1950s operated cash grants schemes) ${ }^{135}$ However, in the 1930s the scheme's focus on providing financial support to patient-members rather than the hospitals was controversial, with the BMICS called upon to justify it at annual general meetings of the British Hospital Contributory Schemes Association in both 1936 and 1937. In doing so, the BMICS's founding Honorary Secretary, Mr J.S. Tudor 'maintained that this matter was entirely outside the province of the Contributory Scheme Movement, as the accounts were separated from those of the ordinary Contributory Scheme, and that the Scheme was being managed by a committee which had no jurisdiction of the Committee of the Bristol Medical Institutions Contributory Scheme and vice versa., ${ }^{136}$

The hospitals were not reassured and became increasingly resentful of this scheme, claiming cash benefits to patients to be inimical to the interests of the Voluntary Hospitals' for diverting funds from the general support of the institutions, and this became a key disagreement as the 
relationship between the BMICS and the voluntary hospitals broke down almost entirely. ${ }^{137}$ Indeed, hospital representatives went so far as suggesting changing its name to Bristol Welfare Association in order that it is completely dis-associated [sic] in the minds of the public from hospital contributory schemes. ${ }^{138}$ Surprisingly, given the concern of the voluntary hospitals, when the BMICS restricted the Extended Benefits Scheme to its members, the BHF felt 'obliged to create a separate Welfare Fund' for its own members. We might say that outright competition for contributors forged a local consensus over what services ought to be provided. ${ }^{139}$

Despite this shared trend for increasingly insurance-style services, both remained organisations firmly rooted in the voluntary sector, in line with the image presented by the cover of the BHF's 1945 report (see figure 3.5), which depicted the various insurance-style schemes as contributing to success in fundraising. This was seen in practice when it took over the administration of the charitable Lord Mayor's Fund in 1941, essentially creating a central clearing house for contributory and charitable donations to the city's voluntary hospitals. ${ }^{140}$ The rival BMICS had also shown itself to be fundraising for the hospitals when, more than a decade earlier, over 1,000 of its collection boxes appeared within ten miles of the city centre in just its first two years. ${ }^{141}$ In addition to this, from 1931 charitable donations from individuals or workpeople's funds could be earmarked for specific institutions, allowing for a traditional philanthropic relationship between the donor and recipient institution to be rolled out to a far broader base of donors. ${ }^{142}$ Perhaps most significantly, while the majority of the BMICS's income would always come from employees and individual contributors, its expenditure was not limited to covering patient payments. ${ }^{143}$ In fact grants to the hospitals matched payments on behalf of their members, either taking the form of donations for specific causes, such as the Bristol Royal Infirmary's Cancer Research Fund, or general grants for the upkeep of the institution. ${ }^{144}$ In neither case can these funds be seen as insurance payments for their members as patients.

\section{Conclusion}

Understanding the almoner and the payment system she administered brings greater clarity to our view of hospital contributory schemes. 




Figure 3.5 Bristol Hospitals Fund schemes depicted as fundraising successes, 1945

The Bristol case suggests the 'consumer choice' generated by reciprocal arrangements between schemes and hospitals, effectively creating a 'voucher' system, that Cherry identified in East Anglia, was far from universal. ${ }^{145}$ In the previous chapter we saw how the various hospitals of Bristol covered largely different medical needs. Even when the local authority turned Southmead into a municipal general hospital, it was really only emergency admissions and maternity cases that were taken in Southmead. By contrast, maternity patients already had a choice between numerous voluntary hospitals, often situated nearby each other in the city centre. ${ }^{146}$ Bristol provided an urban context for a significant concentration of hospitals operating the same or similar admissions policies. Consequently there was little need for any 
contributory scheme 'voucher' arrangement to provide choice between institutions.

More fundamentally, as we have seen, admission was not conditional on either almoner-assessed payment or contributory scheme membership. This removes the fundamental premise for seeing them as effectively private healthcare or medical insurance. Instead, both need to be incorporated into our understanding of the medical philanthropy of the voluntary hospital in the early twentieth century. This requires us to recognise that medical philanthropy was not something static. Indeed, the hospital itself was changing at this time and perceptions of the hospital as a charity changed with it. As the city's first almoner wrote in 1921:

The Bristol Royal Infirmary has been in existence since 1735, as an entirely free Institution and the inhabitants of the City and surrounding district have looked upon it in that light. Charity as represented by voluntary hospitals has become so much part of the established order of things that it is often not regarded as charity at all. It is quite a common occurrence to hear a patient who is receiving free hospital treatment refuse any offer of additional help on the plea that they cannot accept charity. ${ }^{147}$

There were certainly practical changes taking place. However, it is a significant overstatement to view these changes as the end of medical charity. Instead, by offering exemptions from the new payments and maintaining the social encounter that mediated the provision of free hospital care, the almoner was crucial in ensuring these changes amounted to a reinvention, rather than an abandonment, of charitable admission.

The evidence from Bristol's contributory schemes suggests that a working solution was found to balancing fundraising and benefits, although admission was not one of those benefits. Making such fine balances (mis) understood was, however, another matter altogether, and one to which we will return in chapter 5. Whatever the motivation behind membership, hospital contributory schemes were essentially fundraising bodies. Their activities included raising funds for particular campaigns and in some cases grants for the general upkeep of hospitals. Even in their primary function of covering working-class patients' payments they were not playing any role in securing access; rather, they were facilitating voluntary financial contributions on the part of the 
local population. Where admission was a medical matter, the almoner and the contributory scheme both served to negotiate the terms of that admission. It is in this way that they both played a part in operating a new, but still philanthropic, patient contract in the general wards of the hospitals until 1948.

\section{Notes}

1 Sir Alan Garrett Anderson, HC Deb 8 May 1936, vol. 311, c. 2052

2 See especially Steven Cherry, 'Accountability, Entitlement, and Control Issues and Voluntary Hospital Funding c1860-1939', Social History of Medicine, 9:2 (1996), 215; Martin Gorsky, Patterns of Philanthropy: Charity and Society in Nineteenth-Century Bristol (Woodbridge: Boydell \& Brewer Ltd, 1999), pp. 121 and 189.

3 Mary Fissell, 'Charity Universal? Institutions and Moral Reform in Eighteenth-Century Bristol' in Lee Davison, Tim Hitchcock, Tim Keirn and Robert Shoemaker (eds), Still The Grumbling Hive: The Response to Social and Economic Problems in England, 1689-1750 (Stroud: St Martin's Press, 1992), p. 126; Mary Fissell, Patients, Power, and the Poor in EighteenthCentury Bristol (Cambridge: Cambridge University Press, 1991), p. 7.

4 Fissell, Patients, Power, and the Poor, p. 7.

5 Fissell, 'Charity Universal?', p. 121.

6 Fissell, Patients, Power, and the Poor, pp. 74 and 12.

7 Alan Kidd, 'Philanthropy and the "Social History Paradigm"', Social History, 2:2 (1996), 138; Gorsky, Patterns of Philanthropy, p. 121.

8 Elizabeth Gaskell, Mary Barton: A Tale of Manchester Life, 2003 Penguin Classics edition (1848), p. 70.

9 Sanctuary, Association of Hospital Officers Conference, 1925, in Gazette, May 1925, p. 9, cited in Cherry, 'Accountability', p. 224.

10 This system was also widely used in the United States. See Paul Starr, The Social Transformation of American Medicine (New York: Basic Books, 1982), p. 153.

11 Gorsky, Patterns of Philanthropy, p. 189.

12 C Bruce Perry, Voluntary Medical Institutions (Bristol: Bristol Branch of the Historical Association, 1984), p. 15.

13 Royal Free Hospital Archive, RFH/1/2/2, 'History of the Royal Free Hospital', Royal Free Hospital Reports 1848-65, Book A1, Royal Free Hospital Report, January 1849, p. vii cited in Lynsey Cullen, 'The First Lady Almoner: The Appointment, Position, and Findings of Miss Mary Stewart at the Royal Free Hospital, 1895-99', Journal of the History of Medicine and Allied Sciences 68:4 (2013), 559 (original emphasis). 
14 Martin Gorsky, John Mohan, and Martin Powell, 'The Financial Health of Voluntary Hospitals in Interwar Britain', Economic History Review, 55:3 (2002), 476; Martin Daunton, 'Payment and Participation: Welfare and State-Formation in Britain, 1990-1951', Past and Present, 150 (1990), 188-91.

15 Radcliffe Infirmary, Report (1919), p. 11; Centre for Oxfordshire Studies, OXFO 362.1 RADC, "Letter Explaining the Abolition of the "Turns" System at the Radcliffe Infirmary', June 1926.

16 Nick Hayes, "'Our Hospitals"? Voluntary Provision, Community and Civic Consciousness in Nottingham Before the NHS', Midland History, 37:1 (2012), 98-9.

17 Jonathan Reinarz, Health Care in Birmingham: The Birmingham Teaching Hospitals, 1779-1939 (Woodbridge: Boydell Press, 2014).

18 See especially Steven Cherry, 'Beyond National Health Insurance. The Voluntary Hospitals and Hospital Contributory Schemes: A Regional Study', Social History of Medicine, 5:3 (1992), 455-82; Cherry, 'Accountability'; Steven Cherry, 'Before the National Health Service: Financing the Voluntary Hospitals, 1900-1939', Economic History Review, 50:2 (1997), 305-26; Steven Cherry, 'Hospital Saturday, Workplace Collections and Issues in Late Nineteenth-Century Hospital Funding', Medical History, 44:4 (2000), 461-88; Martin Gorsky, John Mohan and Tim Willis, 'Hospital Contributory Schemes and the NHS Debates 1937-46: The Rejection of Social Insurance in the British Welfare State?', Twentieth Century British History, 16:2 (2005), 170-92; Martin Gorsky, John Mohan and Tim Willis, 'From Hospital Contributory Schemes to Health Cash Plans: The Mutual Ideal in British Health Care after 1948', Journal of Social Policy, 34:3 (2005), 447-67; Martin Gorsky, John Mohan, with Tim Willis, Mutualism and Health Care: British Hospital Contributory Schemes in the Twentieth Century (Manchester: Manchester University Press, 2006); Barry M. Doyle, 'Power and Accountability in the Voluntary Hospitals of Middlesbrough 1900-48' in Peter Shapely and Anne Borsay (ed.), Medicine, Charity and Mutual Aid: The Consumption of Health and Welfare, c.1550-1950 (Aldershot: Ashgate, 2006), pp. 207-24; Barry M. Doyle, 'Competition and Cooperation in Hospital Provision in Middlesbrough, 1918-1948', Medical History, 51:3 (2007), 337-56; Barry M. Doyle, 'Labour and Hospitals in Three Yorkshire Towns: Middlesbrough, Leeds, Sheffield, 1919-1938', Social History of Medicine, 23:2 (2010), 374-92.

19 Gorsky and Mohan, Mutualism and Health Care, p. 64; Cherry, 'Beyond', p. 455.

20 Gorsky and Mohan, Mutualism, p. 49. 
21 Bristol Times and Mirror, 2 July 1921, p. 7.

22 Charles Saunders, The Bristol Eye Hospital (Bristol: United Bristol Hospitals, 1960), p. 24; V.J. Marmion, The Bristol Eye Hospital: A Monograph (Bristol, 1987), p. 18; Bristol Homeopathic Hospital, Report for 1937, pp. 25-6.

23 Reinarz, 'Investigating the "Deserving” Poor'.

24 Bristol Children's Hospital, Report for 1920, p. 5.

25 Bristol Children's Hospital, Report for 1921, pp. 20 and 12; Charles Saunders, The Bristol Royal Hospital for Sick Children (Bristol: United Bristol Hospitals, 1961), p.20. A similar issue was noted in nineteenth-century Birmingham in Reinarz, 'Investigating the "Deserving” Poor'.

26 Cherry, 'Insurance', pp. 467 and 464.

27 Bristol Homeopathic Hospital, Report for 1937, p. 5.

28 Mark Abrams, The Conditions of the British People, 1911-1945 (London: Victor Gollancz, 1946), pp. 84-5.

29 Ministry of Labour, Eighteenth Abstract of Labour Statistics of the United Kingdom (London: HMSO, 1926), pp. 104-7.

30 'Minutes of Meeting of Joint Sub-Committee of Bristol Royal Infirmary and Bristol General Hospital on the subject of Paying Patients held at Exchange Chambers, Bristol, on Tuesday, April 10 1921 at 5pm', in BRI, Faculty Minutes 1911-1925, p. 241.

31 BRI, Report for 1926, p. 19.

32 BRI, Report for 1921, p. 10

33 BRI, Report for 1922, p. 21.

34 Ibid., p. 19.

35 Bristol Times and Mirror, 2 July 1921, p. 7.

36 Bristol Homeopathic Hospital, Report for 1937, pp. 25-6.

37 BRI, Report for 1923, p. 21.

38 Cherry, 'Accountability', p. 230.

39 BRI, Report for 1922, p. 21 and Report for 1932, p. 18; BGH, Report for 1933, p. 21.

40 University of Nottingham Library, Manuscripts Department, UHe M1/7, Mins Finance and House Comm., Eye Hospital, 12 June and 10 July 1912; Uhg M/1/4, Report of the Almoner, General Hospital, 6 Oct. 1937, cited in Hayes, 'Our Hospitals?', p. 101.

41 Hayes, 'Our Hospitals?', p. 101.

42 BRI, Report 1921, p. 20. In 1938, the same promise, that nobody had ever been refused treatment from an inability to pay, was be made by the Secretary of the Nottingham General Hospital. See Hayes 'Our Hospitals?', p. 98.

43 BRI, House Committee Minutes, 6 January 1925. 
44 John Stewart, "“The Finest Municipal Hospital Service in the World”?: Contemporary Perceptions of the London County Council's Hospital Provision, 1929-1939', Urban History, 32:2 (2005), 327-44.

45 Parsons, 'Bristol', p. 142.

46 BCM, 1 January 1930.

47 Barry M. Doyle, A History of Hospitals in Middlesbrough (Middlesbrough: South Tees NHS Hospitals Trust, 2003), p. 62.

48 Barry M. Doyle, The Politics of Hospital Provision in Early 20th-Century Britain (London: Pickering and Chatto, 2014), p. 64.

49 BCM, 1 January 1930.

50 BCM, 10 October 1933, Report of the Health Committee, 26 September 1933.

51 Almoner's Report, Southmead Hospital, in BMOH, Report for 1937, p. 156.

52 Lara Marks, Metropolitan Maternity: Maternal and Infant Welfare Service in Early Twentieth Century London (Amsterdam: Rodopi, 1996).

53 BRI, Faculty Minutes, 20 November 1919; Bristol Children's Hospital, Report for 1920, pp. 11-12.

54 Ibid., Faculty Minutes, 20 July 1918; General Committee Minutes, 23 July 1918.

55 Ibid., General Committee Minutes, 13 January 1920.

56 Bruce Perry, Voluntary Medical Institutions, p. 6; Charles Saunders, The United Bristol Hospitals (Bristol: United Bristol Hospitals, 1965), p. 63.

57 Ibid., General Committee Minutes, 11 November 1919.

58 Ibid., General Committee Minutes, 9 November 1920.

59 Bristol Times and Mirror, 2 July 1921, p. 7.

60 Hayes, 'Our Hospitals?', pp. 98-9.

61 Angela Simmons, A Profession and Its Roots - The Lady Almoners (Michelangelo Press, 2005), https://www.kcl.ac.uk/sspp/policyinstitute/scwru/swhn/publications/Simmons-A-Profession-and-ItsRoots-The-Lady-Almoners.pdf, accessed 25 April 2016. Similarly, see E. Moberly Bell, The Story of Hospital Almoners: The Birth of a Profession (London: Faber \& Faber, 1961).

62 Phyllis Willmott, '1895-1945: The First 50 Years' in Joan Baraclough, Grace Dedman, Hazel Osborn and Phyllis Willmott (eds), 100 Years of Health Related Social Work 1895-1995: Then - Now - Onwards (Birmingham: BASW, 1996), pp. 1-11.

63 Keir Waddington, 'Unsuitable Cases: The Debate over Outpatient Admissions, the Medical Profession and Late-Victorian London Hospitals', Medical History, 42:1 (1998), 42-5.

64 See Cullen, 'First Lady Almoner'. 
65 Chris Nottingham and Rona Dougall, 'A Close and Practical Association with the Medical Profession: Scottish Medical Social Workers and the Social Medicine, 1940-1975', Medical History, 51:3 (2007), 309-36.

66 Elaine Thomson, 'Between Separate Spheres: Medical Women, Moral Hygiene and the Edinburgh Hospital for Women and Children' in Steve Sturdy (ed.), Medicine, Health and the Public Sphere in Britain 1600-2000 (London, 2002), pp. 116-17.

67 Doyle, Politics of Hospital Provision, pp. 70-1.

68 Dorothy Manchée, Whatever Does the Almoner Do? (London: Bailliere, Tindall and Cox., 1946), preface.

69 Ibid., pp. 8-9.

70 I.F. Beck, The Almoner: A Brief Account of Medical Social Service in Great Britain (London: Council of the Institute of Almoners, 1948), p. 50; The Hospital Almoner: A Brief Study of Hospital Social Service in Great Britain (London: Hospital Almoners Association, 1935), p. 39. For an in-depth consideration of Mary Stewart's role as the first hospital almoner see Cullen, 'Almoner'.

71 Beck, Almoner, pp. 49-50; Almoner: Brief Study, p. 34.

72 Willmott, '50 Years', pp. 3-5.

73 Alan Moncrieff, 'Preface' in Beck, Almoner, p. 3.

74 Willmott, '50 Years', p. 7.

75 Beck, Almoner, p. 4.

76 Almoner's Report in the Addenbrooke's Hospital, Cambridge, Report for 1934-1935, p. 18.

77 Elizabeth Gloyne, Social Workers Speak Out, 1981, 8, Modern Records Centre [hereafter MRC], University of Warwick, http://www2.warwick. ac.uk/services/library/mrc/explorefurther/speakingarchives/socialwork/929.publ_no_9_gloyne.pdf, accessed 11 March 2016.

78 Enid Warren, Social Workers Speak Out, 1981, 13, MRC, University of Warwick, http://www2.warwick.ac.uk/services/library/mrc/ explorefurther/speakingarchives/socialwork/929.publ_no_21_warren. pdf, accessed 11 March 2016.

79 Jean Snelling, Social Workers Speak Out, 1980, 21, MRC, University of Warwick, http://www2.warwick.ac.uk/services/library/mrc/explorefurther/speakingarchives/socialwork/929.publ_no_18_j_snelling.pdf, accessed 11 March 2016.

80 Beck, Almoner, pp. 6-7, 10-11, 17-18 and 43; Almoner: Brief Study, pp. 55-67; D.A. Dow, M.M. Leitch and A.F. MacLean, From Almoner to Social Worker: Social Work at Glasgow Royal Infirmary, 1932-1982 (Glasgow: Glasgow Royal Infirmary, 1982), p. 10.

81 Dow, et al., Social Worker, p. 9. 
82 Marjorie McInnes, 'Preface' in Dow, et al., Social Worker, p. 4.

83 BHH, Report for 1937, p. 25.

84 BRI, Report for 1935, p. 20.

85 BRI, Report for 1921, p. 20.

86 This was noted for Bristol in Gorsky, 'Bristol's Hospital Services', ch. 5.1. See also Martin Gorsky, Martin Powell and John Mohan, 'British Voluntary Hospitals and the Public Sphere: Contribution and Participation before the National Health Service' in Sturdy (ed.), Public Sphere, p. 124.

87 BRI, Report for 1922, pp. 21-2.

88 For example, see BRI, Report for 1924, p. 21.

89 BRI, Report for 1927, p. 17.

90 BRI, Report for 1931, p. 18.

91 BRI, Report for 1936, p. 26; Report for 1938, p. 18; BGH, Report for 1927, p. 20.

92 BRI, Report for 1930, p. 18; Report for 1937, p. 22.

93 BRI, Report for 1937.

94 BRI, Report for 1921, p. 20.

95 Nottingham and Dougall, 'Association', p. 309.

96 Andrew Scakville, 'Thomas William Cramp, Almoner: The Forgotten Man in a Female Profession', British Journal of Social Work, 19:1 (1989), 95-110.

97 For some of the key themes in the literature on women's philanthropic work, see F.K. Prochaska, Women and Philanthropy in Nineteenth-Century England (Oxford: Clarendon Press, 1980); Megan Smitley, The Feminine Public Sphere: Middle-Class Women and Civic Life in Scotland, c.1870-1914 (Manchester: Manchester University Press, 2009); Dorice Williams Elliott, The Angel Out of the House: Philanthropy and Gender in NineteenthCentury England (London: University of Virginia Press, 2002).

98 A. Frederic White, 'Hospital Almoners' in Every Woman's Encyclopaedia: Articles Relevant to a Woman's Life in Society (London, 1910-1912), http:/ / chestofbooks.com/food/household/Woman-Encyclopaedia-3/Hospital-Almoners.html, accessed 25 April 2016. According to advertisements in The Times the average annual wage for a general servant in 1907 was $£ 19$ 10s. Elizabeth Roberts, Women's Work, 1840-1940 (Cambridge: Cambridge University Press, 1988), p. 22.

99 Ray Strachey, Careers and Openings for Women: A Survey of Women's Employment and a Guide for Those Seeking Work (London: Faber and Faber, 1935), pp. 223 and 233.

100 Alison Oram, Women Teachers and Feminist Politics, 1900-39 (Manchester: Manchester University Press, 1996), p. 25; Strachey, Careers and Openings, pp. 71-2.

101 Strachey, Careers and Openings, pp. 81 and 70. 
102 Ibid., pp. 158-9, 223 and 240.

103 Modern Records Centre [hereafter MRC], Institute of Hospital Almoners [hereafter IHA], Report for 1942, p. 10.

104 BRI, Report for 1937, p. 21.

105 M, Institute of Hospital Almoners, Reports for 1938, p. 17; and Report for 1939, p. 15.

106 Jane Lewis, Women and Social Action in Victorian and Edwardian England (Stanford: Stanford University Press, 1991), p. 305.

107 Jane Lewis, 'Women, Social Work and Social Welfare in TwentiethCentury Britain: From (Unpaid) Influence to (Paid) Oblivion?' in Martin Daunton (ed.), Charity, Self-Interest and Welfare in the English Past (London: UCL Press, 1996), p. 205.

108 Cited in Pat Thane, 'What Difference Did the Vote Make?' in Amanda Vickery (ed.), Women, Privilege and Power: British Politics, 1750 to the Present (Stanford: Stanford University Press, 2001), p. 284.

109 Beck, Almoner: Brief Study, p. 47.

110 Beck, The Almoner, p. 5.

111 Beck, Almoner, pp. 8-9; Almoner: Brief Study, p. 47.

112 Beck, Almoner: Brief Study, p. 41.

113 Beck, Almoner, p. 5.

114 Manchée, Whatever, p. 9.

115 Dow, et al., Social Worker, p. 10.

116 Beck, Almoner, p. 60.

117 Ibid., p. 61; Cherry, 'Accountability', p. 230.

118 Rayner Garner, from the UK Midwifery Archives on Midwifery Matters, the website of the Association of Radical Midwives, http://www .midwifery.org.uk/?page_id=655, accessed 25 April 2016.

119 Bella Aronovitch, Give it Time. An Experience of Hospital, 1928-1932 (London: Andre Deutsch, 1974) cited in Deborah Brunton (ed.), Health, Disease and Society in Europe 1800-1930: A Source Book (Manchester: Manchester University Press, 2004), p. 285.

120 Lucinda McCray Beier, For Their Own Good: The Transformation of English Working-Class Health Culture, 1880-1970 (Columbus: Ohio State University Press, 2008), p. 133.

121 Jim Cobley, 'Happy Birthday NHS', TSSA (Transport and Salaried Staffs' Association) Journal, August/September 2008, http://www.tssa.org.uk/ article-269.php3?id_article=4349, accessed 9 September 2010.

122 BGH, Report for 1921, p. 17; BRI, Reports for 1921-1938.

123 Gorsky, Patterns of Philanthropy, p. 231.

124 Bristol Contributory Welfare Association [hereafter BCWA], Extracts from British Hospital Contributory Schemes Association Points of Policy 
for Hospital Contributory Schemes, 1937 (original emphasis). Gorsky and Mohan acknowledge schemes did not have the 'legal position' of insurance bodies in Mutualism and Health Care, p. 65.

125 Bruce Perry, Voluntary Medical Institutions, p. 5.

126 See Gorsky and Mohan, Mutualism and Health Care, pp. 25-31.

127 Robert Tressell, The Ragged Trousered Philanthropists (London: Flamingo Modern Classics edn, 1997 [1914]), p. 221.

128 BSC, Bristol Hospitals Commission, BHF evidence, Representatives, 1926.

129 BRI, Faculty Minutes, 8 December 1919.

130 BRI, House Committee Minutes, 4 September 1919.

131 BRI, General Committee Minutes, 21 April 1925. See Steve Sturdy, 'The Political Economy of Scientific Medicine: Science, Education and the Transformation of Medical Practice in Sheffield, 1890-1922', Medical History, 3:6 (1992), 144-5.

132 BSC, DM980 (30), Bristol Hospitals Commission, BHF evidence, appendix 1. 'Report of Meeting of representatives of Bristol Royal Infirmary, Bristol General Hospital and Sub-Committee of Employees to consider the suggested Contributory Scheme' [hereafter Representatives], 30 July 1926.

133 For further details see George Campbell Gosling, " Open the Other Eye”: Payment, Civic Duty and Hospital Contributory Schemes in Bristol, c.1927-1948', Medical History, 54:4 (2010), 475-94.

134 BMICS, Report for 1934; Rules adopted, December 1936.

135 BMICS, Report for 1935, p. 5; Gorsky and Mohan, Mutualism and Health Care, p. 196.

136 BCWA, 'At the 24th Meeting of the Executive Committee of the British Hospitals Contributory Schemes Association', 17 July 1936.

137 BSC, Bristol Hospitals Commission, BHF evidence, 'Communication from the Joint Committee of Hospital Representatives to the Bristol Medical Institutions Contributory Scheme (Inc.)'.

138 BSC, DM980 (28), Contributory Schemes Conference Dinner 1942, Bristol \& District Divisional Hospitals Council, schedule 2.

139 BSC, DM980 (35), BHF, 'Summarised Diary of Negotiations to Establish One Central Hospitals Contributory Scheme in Bristol'.

140 BSC, DM980 (12), Lord Mayor's Hospital Fund, Bristol \& District Divisional Hospitals Council Sub-Committee, Report of meeting of standing committee sub-committee and the Lord Mayor's Fund sub-committee, 16 November 1942.

141 BMICS, Report for 1928, p. 8.

142 BMICS, Reports for 1931-1945. 
143 BMICS, Reports for 1928-1945.

144 BMICS, Report for 1934, p. 6; Report for 1929, pp. 8-9.

145 Cherry, 'Insurance', p. 475.

146 Cope, et al., Survey, pp. 31 and 178.

147 BRI, Report for 1921, p. 20. 